\title{
Flußumlegung im Prättigau (Kanton Graubünden), seismisch untersucht
}

\author{
Alfred Schneider
}

\section{Einleitung}

Oftmals ist die epigenetische Entstehung heutiger Flußläufe in den Alpen aus der Gesamtsituation sofort ersichtlich oder darf als wahrscheinlich postuliert werden, auch wenn der Nachweis nicht in aller Strenge gelingt. Breiten sich aber mächtige Schuttmassen in den Tälern aus, wie dies im Prättigau bei Fideris der Fall ist, dann gestaltet sich die Beurteilung der Verhältnisse schwieriger, weil die bestehenden Oberflächenformen auf mehr als eine Weise entstanden sein können. Unser Objekt, von dem die Rede sein soll, ein mächtiger Schuttkuchen, überragt um 100 bis $150 \mathrm{~m}$ das Tal, welches dadurch in ein unteres Becken von Jenaz und ein oberes von Küblis gegliedert wird.

Die unten beschriebene Untersuchung wurde zwischen diesen beiden Ortschaften angesetzt, um über den Schuttkörper Aufschluß zu erhalten und damit auch das Problem des seitlichen Flußlaufes ganz an der nördlichen Flanke des Tales zu klären. Der Autor beabsichtigt lediglich, die erhaltenen Ergebnisse vorzulegen und die sich aufdrängenden naheliegenden Schlußfolgerungen zu ziehen.

Die Frage nach der Beschaffenheit der Querstruktur im Tale bei Fideris tauchte in allgemeiner Form als Konsequenz straßenbaulicher Detailprobleme auf, nämlich: Inwieweit beteiligt sich das anstehende Gestein, der Prättigauflysch, am Aufbau der Terrasse von Fideris, wo die Ebenen des Talgrundes an beiden Seiten abrupt endigen? Es stehen vor allem zwei Möglichkeiten zur Diskussion. Einerseits sind glazial bedingte Felsriegel mit aufgesetzter Moräne in den Alpen keine Seltenheit und könnten auch hier eine Rolle spielen, andererseits vermutete aber bereits Krasser (1939) in seiner morphologischen Arbeit über das Prättigau den epigenetischen Charakter des Flußbettes unterhalb von Küblis.

Angesichts dieser Situation entschloß sich der Autor, im denkbar günstig gelegenen, 60-70 m tief eingeschnittenen Arieschgraben ein refraktionsseismisches Profil über die $700 \mathrm{~m}$ lange Strecke zwischen den Felsflanken zu beiden Seiten anzuordnen. Dabei wurden Seismometerabstände von $30 \mathrm{~m}$ gewählt und zur Anregung der seismischen Erschütterungswellen Sprengungen an 5 Stellen gezündet. Zwar bedingte das reichlich strömende Wasser ein hohes Ausma $\beta$ an störender Boden- unruhe; dennoch gelang es, auf den Seismogrammen auswertbare Ersteinsätze der seismischen Impulse zu erzielen.

Die Laufzeitmessungen im Gelände beanspruchten im Juli 1972 knapp einen Arbeitstag. An dieser Stelle sei den Herren Mac Allister und D. Schneider für ihre Mitarbeit gedankt. Was die anschlieBende rechnerische Behandlung der gemessenen Laufzeiten anbelangt, so verweisen wir auf die einschlägige Fachliteratur, z. B. Refraction Prospecting (1967).

\section{Ergebnisse}

An dieser Stelle sei vorweggenommen, daß die Auswertung der Laufzeitmessung Krassers Auffassung der Epigenese offensichtlich bestätigt. Die Region Fideris birgt nämlich einen wohl ausgebildeten Felstrog mit Lockergesteinfüllung.

Nördlich Stralegg durchbricht der Arieschbach einen Felsriegel (die ehemalige Talflanke) und mündet auf zirka $785 \mathrm{~m}$ Höhe in die Landquart, wo auch die rezente Felssohle des Tales zu suchen ist. Ungefähr $500 \mathrm{~m}$ südwestlich dieser Stelle (vgl. Figur) senkt sich die Obergrenze des Felsens bis auf $740 \mathrm{~m}$ hinab. Wie aus dem Profil hervorgeht, befindet sich zwischen Stralegg und Fideris ein wannenförmiger Einschnitt, dessen Sohle immerhin noch ca. $100 \mathrm{~m}$ unter dem heutigen Bett des Arieschbaches liegt.

Wie die Felskoten in der Tallängsrichtung zusammenhängen, wäre interessant zu wissen, kann mangels genauer Kenntnisse zurzeit aber nur geschätzt werden. Bekannt sind einzig die Höhen des Talbodens. Unterhalb Küblis liegt der Talgrund bei $790 \mathrm{~m}$; bei Fideris Station sind es $744 \mathrm{~m}$ ü. M. Wird arbiträr an beiden Stellen die Dicke des Quartärs mit 20 m veranschlagt und in Abzug gebracht, so müßten die Felshöhen in entsprechender Folge lauten:

Fideris Station $724 \mathrm{~m}$, Arieschbachgraben $740 \mathrm{~m}$, Küblis/Dalfazza $770 \mathrm{~m}$. Immerhin passen solcherart geschätzte Niveaus anscheinend ohne Widersprüche zusammen.

Die Grenze zwischen Flysch und quartären Lockermassen prägt sich in der Refraktionsseismik durch den Geschwindigkeitskontrast beider Medien aus. 


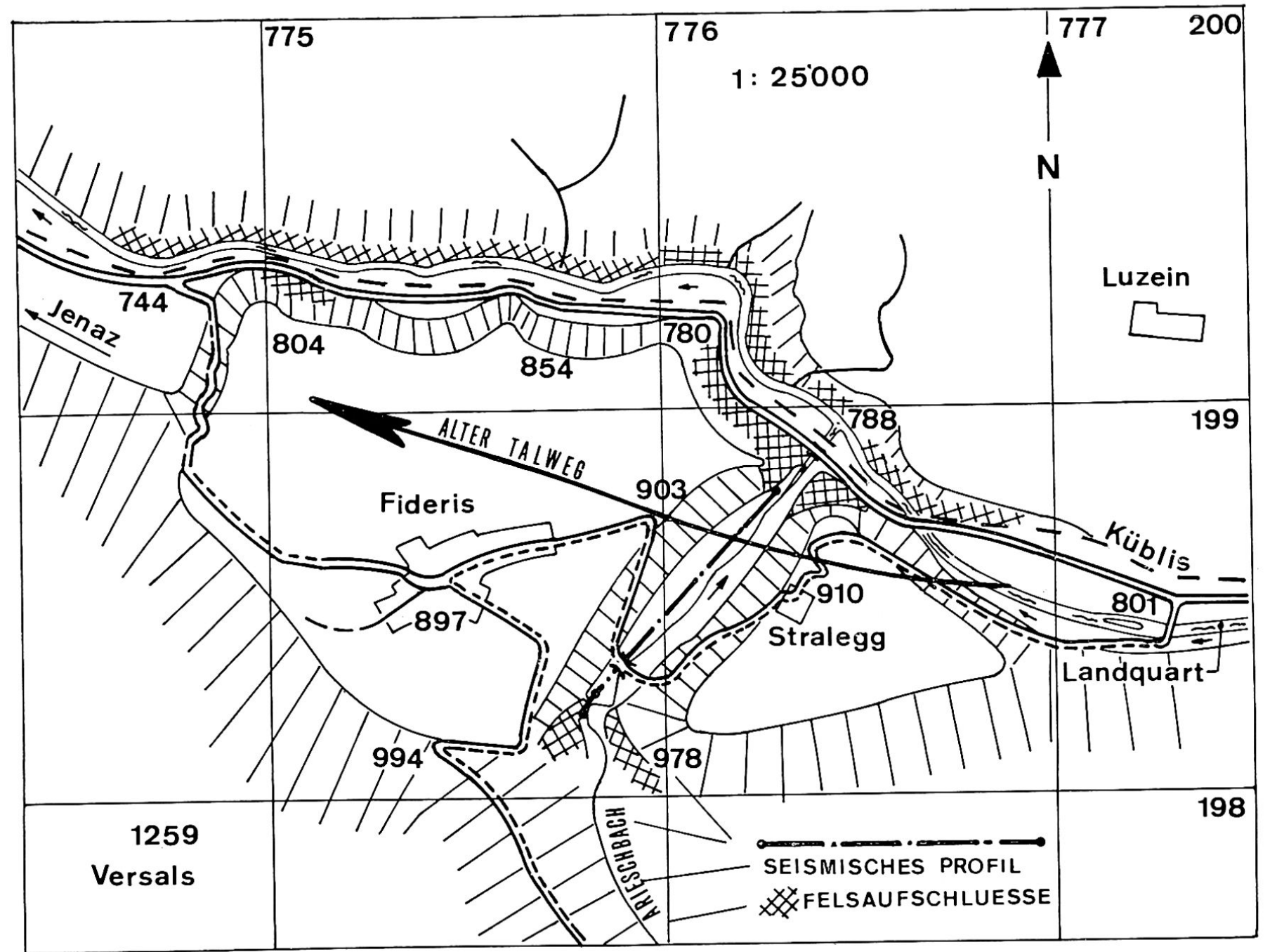

Fig.1

ГNE

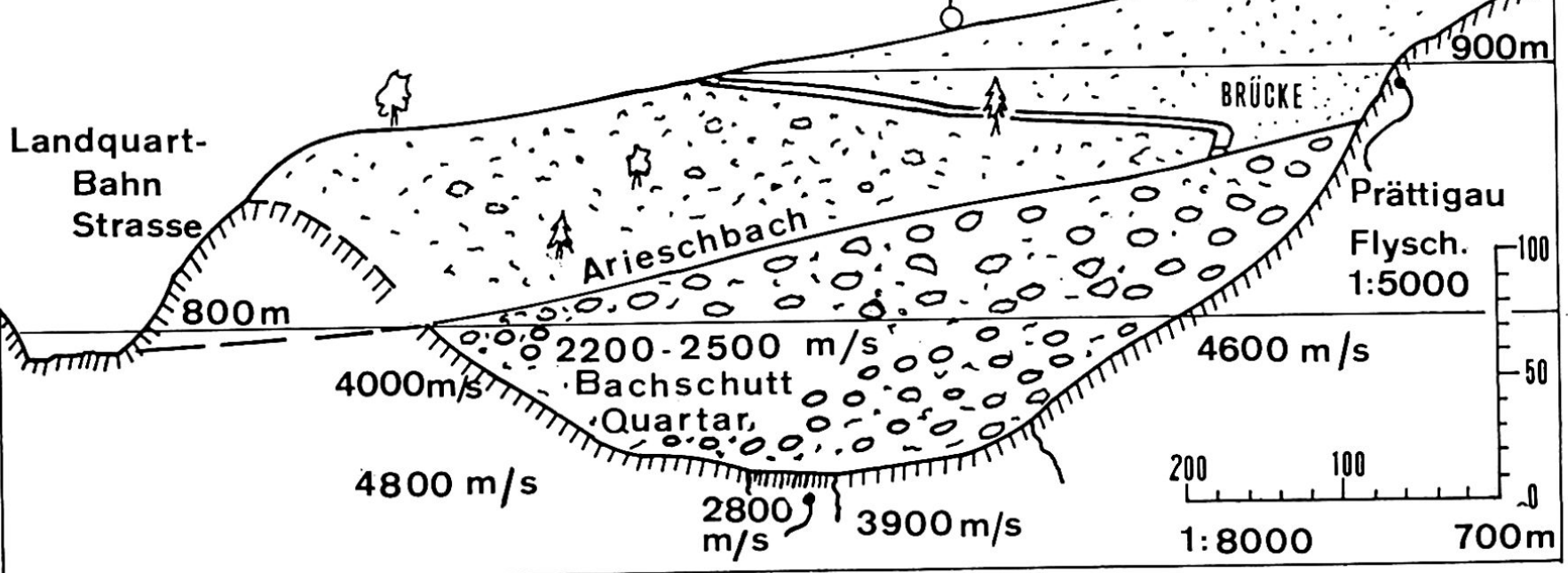

Fig. 2

Figur 1. Situation $1: 25$ 000. Prättigau zwischen Jenaz und Küblis an der Strecke Landquart-KlostersDavos

Figur 2. Seismisches Profil im Arieschbachgraben durch den Schuttfächer von Fideris. 1,6 fach überhöht. Ansicht von NW. Mutmaßlicher Kontakt zwischen Flysch und quartärem Bachschutt 
Im Prättigauflysch beträgt die Fortpflanzungsgeschwindigkeit der sogenannten Kopf- oder Longitudinalwellen $3800-4600 \mathrm{~m} / \mathrm{s}$, im Mittel ca. 4000 $\mathrm{m} / \mathrm{s}$. Lokal sind Schwankungen zu verzeichnen, von denen die markanteste im Rinnentiefsten liegt. Auf einer Breite von 50-60 m vermindert sich die Geschwindigkeit auf nur $2800 \mathrm{~m} / \mathrm{s}$, also auf einen sehr geringen Wert, verglichen mit dem benachbarten Fels. Zur Erklärung des Befundes kommen drei Deutungen in Frage:

1. An der fraglichen Stelle schiebt sich stratigraphisch eine weichere Gesteinsschicht ein.

2. Das Profil erfaßt eine tektonisch beanspruchte Zone, wo der Fels mechanisch beeinträchtigt wurde.

3. Im alten Tale räumte die Erosion zusätzlich noch eine Rinne aus, welche relativ kompakten, möglicherweise glazial gepreßten Schutt enthält.

Ein vergleichbarer, ebenfalls mit der Seismik untersuchter Talquerschnitt existiert in den Tauern Kärntens, wo in der entsprechenden Rinne Grundmoräne erbohrt wurde. Daher neigt der Verfasser zur Ansicht, daß der Existenz jener zusätzlichen Schlucht am Grunde des alten Tallaufes einige Wahrscheinlichkeit zukommt. In der Auffüllung des Troges beobachteten wir Wellengeschwindigkeiten zwischen 2200 und $2500 \mathrm{~m} / \mathrm{s}$, die das übliche Mittel von Bachschutt - $2100 \mathrm{~m} / \mathrm{s}$ etwa - deutlich ïbertreffen. Die Annahme, daß Grundwasser den Schutt im Profilbereich durchnäßt, drängt sich geradezu auf. Durch die erhöhten Geschwindigkeitswerte, welche auch andere, vergleichbare Objekte in den Alpen kennzeichnen, werden heikle Fragen der Grundwasserverhältnisse und der Einstufung der lockeren Gesteine nach Art und Genese auf- geworfen. Ob im vorliegenden Falle von Rückzugmoränen, periglazialen Schottern, überfahrenen und verfestigten älteren Moränen oder von unsortierten Wildbachsedimenten die Rede sein muß, bleibt zunächst völlig offen.

Aus dem vorgelegten Beobachtungsmaterial darf man wohl schließen, daß mit einem Felsriegel bei Fideris selbst wohl kaum zu rechnen ist, sondern $\mathrm{da} ß$ das alte Tal, welches auch der Gletscher benützt haben dürfte, mitten durch die heutige Terrasse von Fideris verläuft. Anscheinend vermochte der Arieschbach dank zeitweise gesteigertem Geschiebetransport die Landquart nach Norden abzudrängen, wo sie sich inzwischen einschneiden konnte. Wir hätten es also mit einer Flußumlegung zu tun. Dem Spezialisten bleibt überlassen, die Ereignisse zeitlich zu ordnen und zu erwägen, wie sich der Stau talaufwärts bei Küblis auswirkte.

\section{Literatur}

Baier Fr. (1912): Über Schottervorkommen und Flußverschiebungen im Prättigau. Jb. Natf. Ges. Grb., 53, Chur.

Baier Fr. (1926): Beiträge zur Morphologie und Glaziologie im Prättigau. Diss. Zürich/Überlingen. Krasser L. (1939): Eiszeitliche und nacheiszeitliche Geschichte des Prättigau. Gießen.

Refraction Prospecting (1967): Verschiedene Autoren. Hg.: SEG, Tulsa Oklahoma.

Adresse des Verfassers:

Dr. A. Schneider, Geologe

Bergstraße 16, 3028 Bern 